\title{
Methylene Blue and Dialysis-Related Hypotension
}

\author{
Wisler J. R. and Stawicki S. P. A. \\ The Ohio State University Columbus, \\ United States
}

\section{Introduction}

End stage renal disease (ESRD) affects over 400,000 Americans, and over 8 million have chronic renal insufficiency [1]. Chronic renal insufficiency (CRI) describes a continuum of impaired renal function based on several parameters including glomerular filtration rate and serum creatinine. As renal function deteriorates, the risk of all-cause mortality increases [1]. The most prevalent form of renal replacement therapy is hemodialysis (HD), with over $75 \%$ of ESRD patients being treated with this modality $[2,3]$. Patients requiring chronic HD have been noted to experience an increase in cardiovascular morbidity and mortality [4]. In fact, between $10-20 \%$ of patients who require HD die each year and approximately $45 \%$ of these deaths are attributable to cardiovascular causes [2,3]. Hemodialysis itself is associated with substantial morbidity, including complications related to vascular access and those inherent to the HD procedure itself.

One of the most common complications of hemodialysis is intradialytic hypotension (IDH), which occurs in approximately $25 \%$ of HD sessions [5]. There are several therapeutic options available for the treatment of IDH. However, "resistant" forms of IDH do occur and a multimodality approach is usually necessary in such cases. The aim of this chapter is to discuss IDH and outline existing clinical approaches to IDH. Specifically, we will focus on the use of methylene blue (MB) in the treatment of IDH. Methylene blue, a nitric oxide pathway mediator, has shown promise in prevention or treatment of IDH in difficult-totreat cases $[6,7]$.

\section{Overview of intradialytic hypotension}

IDH is seen in approximately $20-30 \%$ of hemodialysis sessions and is an independent risk factor for mortality [8]. During a typical HD session, an ultrafiltrate volume of 5 liters or greater may be removed with a concomitant $10-20 \%$ reduction in plasma volume $[9,10]$. Intradialytic hypotension is likely multifactorial, and the inability of the cardiovascular system to adequately respond to the reduction in circulating plasma volume is among the leading factors.

Most patients are able to compensate for the ultrafiltration fluid losses by "mobilizing" fluid from extravascular/interstitial space, and tissue hydration state has a strong influence on changes in plasma volume during fluid removal and subsequent repletion [11]. In cases 
where IDH occurs, available strategies include a combination of vasopressor administration, intravascular volume expansion with intravenous colloid or crystalloid solutions, positional patient changes, and discontinuation of ultrafiltration [12]. Detailed discussion of the underlying physiology and therapies available to treat IDH will now follow.

\subsection{Physiology of intradialytic hypotension}

Intradialytic hypotension can have very serious sequelae, up to and including the development of life-threatening end-organ (i.e., cardiac, cerebral) hypoperfusion [12]. Factors contributory to IDH can be broadly divided into those related to the HD procedure and those related to underlying patient condition(s) [12]. Patient related factors, the focus of this chapter, can be further divided into cardiac (i.e., left ventricular hypertrophy, chronic volume overload, anemia (acute or chronic), diastolic and systolic dysfunction, cardiac arrhythmias, ischemic myocardial syndromes) and vascular (i.e., vasoplegia or impaired maintenance of appropriate vascular tone/systemic vascular resistance) [7, 12]. Hemodialysis related factors include the ultrafiltration rate, possible intra-procedural blood loss, and dialysate temperature profile $[12,13]$.

We will focus on the vascular-related aspects if IDH, concentrating on the vasoplegia associated with the HD procedure. The amount of fluid available in the interstitial space for "vascular refilling" is the one of the primary determinants of IDH. In the presence of excess fluid in the interstitial space, the patient is theoretically more likely to tolerate higher volumes of ultrafiltrate removal [11]. Conversely, patients with relatively smaller amounts of volume in the interstitial space are more susceptible to even small amounts of volume removal. Therefore the determination of the patient's true dry weight is important to planning the amount of ultrafilatrate removal $[14,15]$. It is important to remember that fluid shifts from the interstitial space to the intravascular space constitute a dynamic process and exhibit anatomic variations. For example, intravascular refilling is more vigorous in lower extremities because of the relative excess of extracellular fluid [16].

During ultrafiltration, the body's initial response to volume reduction involves sympathetic mediated vasoconstriction [17]. This vasoconstriction shifts blood flow away from dermal circulation and reduces heat loss. However, this response may not always be sufficient, either due to impaired sympathetic response itself or excessive production of endogenous vasodilators [18]. Chromogranin A levels, which are co-released with catecholamines, are decreased significantly in the post-HD plasma of patients with IDH compared to patients with stable blood pressures [19]. In addition, it has been suggested that patients with significant uremia have autonomic dysfunction that may be due to chronic hyperkalemic depolarization [20].

Endothelial cells and vascular myocytes release adenosine, which also has been implicated in the development of IDH [21]. It is hypothesized that during dialysis there are local areas of tissue ischemia that release adenosine in response. Antagonism of the A1 and A2 adenosine receptors in patients with frequent IDH has been shown to reduce the incidence modestly [21]. Also, peripheral blood mononuclear cells show greater expression of A2A receptors in IDH-prone patients [22].

Patients undergoing HD tend to experience a net increase in body temperature [23, 24]. Core temperature continues to increase throughout the dialysis procedure and may be associated with impaired sympathetic response before the development of IDH [25]. Isothermic HD may improve patient hemodynamics and may help prevent IDH [24]. It is important to note 
that the protective hemodynamic effects of cool dialysate may be most pronounced among patients with lower baseline (i.e., pre-HD) body temperatures [26].

Additional aspects of vasoplegia associated with HD in the context of nitric oxide (NO) pathways will be discussed in subsequent sections, along with the role of methylene blue (MB) as a potential therapeutic agent in this setting.

\subsection{Determination of dry weight and intravascular volume}

The dry weight of a given patient can be difficult to determine and can fluctuate depending on any concurrent acute and chronic illnesses [14]. Several methods of estimating dry weight exist and will be discussed in this section. Commonly used techniques are based on intravascular pressure measurements, bioimpedance determination, arterial waveform analysis, and various sonographic techniques [27-29]. Specific methods include blood volume monitoring with ultrafiltration pulses, central venous and other invasive vascular pressure measurements, ultrasound measurements of the inferior vena cava (diameter and/or collapsibility) or direct bioimpedance measurements (whole-body, segmental, calf) [27-29]. Of note, the use of invasive blood volume monitoring devices has been associated with greater nonvascular and vascular access related complications and mortality [30]. Recent developments in the area of intravascular monitoring and estimation of dry weight and intravascular volume favor the use of minimally invasive or non-invasive modalities such as ultrasonography [31]. Techniques such as the pulmonary artery catheter are becoming less popular.

\subsection{The role of nitric oxide in intradialytic hypotension}

Analyses of plasma from patients identified to be at high risk of IDH suggest that this group may have chronic elevations in plasma nitrites as well as significantly elevated nitrite production [32]. Hemodialysis itself is associated with increased nitric oxide (NO) production [33]. When blood is exposed to hemodialysis membranes, endothelial cells show enhanced expression of inducible nitric oxide synthase (iNOS) mRNA in murine models [34]. In addition, uremic platelets produce increased amounts of NO [35]. It is speculated that cytokines, including IL-1 $\beta$ and TNFa, released during HD by activated mononuclear cells cause activation of NOS. Interestingly, significant increases in NO production are noted in patients who experienced a hypotensive episode during HD when compared to those that did not experience hypotension, suggesting a causal relationship [6]. However, the exact nature of this relationship remains to be elucidated.

NO is produced by two types of NO synthase (NOS) [7]. One exists in the endothelium and is constitutively active (eNOS). The other type is the inducible (iNOS) and exists in various tissues and cell types. Upregulation of iNOS results in increased NO production and generation of cGMP [7]. This can have profound effects on both the vasculature and myocardium.

In end stage renal disease, not only is there in increase in baseline NO production, there is also an increase in inhibitors of NO, namely asymmetric dimethylarginine (ADMA) [36]. It turns out these inhibitors are dialyzable, which suggests that disturbances within the baseline interplay between specific activators and inhibitors during HD may contribute to hemodynamic instability [36, 37]. Direct serum measurements during HD confirm higher nitrate generation, which combined with a decrease in inhibitory factors may lead to IDH. 
In addition to the vasodilatory effects of NO, hypotension may also result from NO's negative inotropic properties [38]. Cholinergic agonists are known to elevate cGMP levels in cardiac myocytes and cGMP analogs may also produce profound negative chronotropic effects [39]. Exposure of cardiac myocytes to carbachol, a cholinergic agonist, results in suppressed contractility and chronotropy as well as profoundly increased levels of cGMP. This effect can be ameliorated by co-administration with methylene blue (MB) which suggests that NO dependent pathways may be involved [39]. Schematic representation of MB mechanism of action as well as pertinent metabolic pathways can be seen in Figure 1.

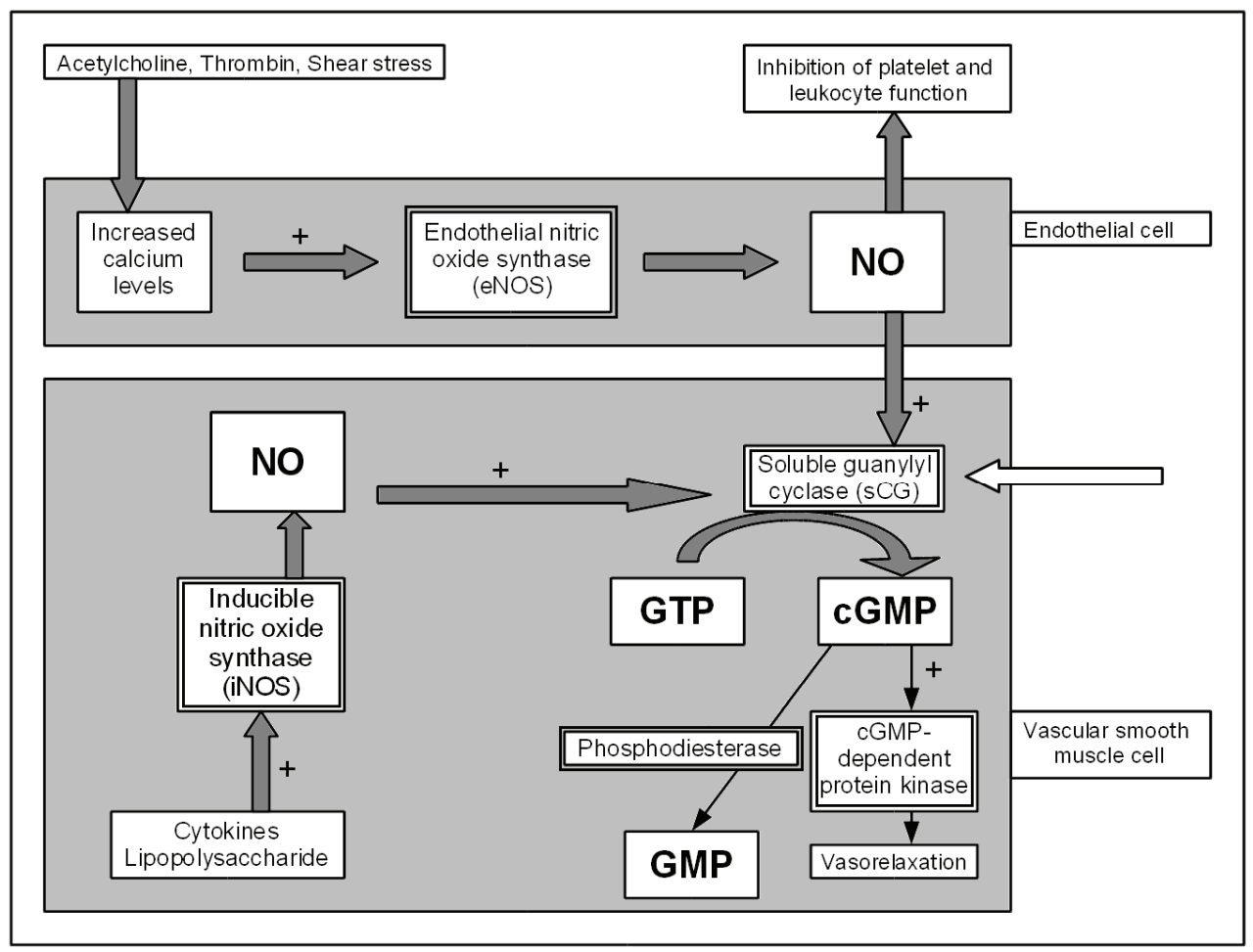

Fig. 1. Schematic representation of NO/cGMP-dependent pathways. Note the endothelial (eNOS) and inducible (iNOS) isoforms of the nitric oxide synthase (NOS) and their associated functional steps. Methylene blue inhibits (white arrow on right) the action of soluble guanylyl cyclase (sGC) and thus prevents vasodilation. Adapted from Bosoy et al [65].

\subsection{Treatment for intradialytic hypotension}

Evidence shows that episodes of intra- and post-dialytic hypotension are associated with increased morbidity and mortality [8]. This makes treatment and prevention of IDH an important part of both short- and long-term HD strategy. Several approaches to this problem exist and will be discussed in this section. 
At the core of IDH is uncompensated response to reduction in circulating blood volume [40]. The patient may exhibit a blunted response to this reduction or the reduction may be too large to mount an effective response. Active monitoring of the dialysis patient's blood volume can provide real-time data to the clinician concerning the patient's volume status. Monitoring usually includes hematocrit, total protein and hemoglobin measurements, which cumulatively provide an estimate of total blood volume [41]. While the physiologic response to blood volume reduction varies considerably between patients, blood volume monitoring allows the clinician to tailor the treatment so the maximal tolerated blood volume changes are not exceeded. Clinical evidence shows that based on blood volume monitoring physicians are able to identify this maximum tolerated blood volume change in approximately $70 \%$ of patients, and the majority of hypotensive episodes occurred when this value is exceeded [42]. However, in almost $30 \%$ of patients such value could not be determined, suggesting that blood volume monitoring alone may not be sufficient for predicting risk of IDH in all patients. Ultrafiltration rate is also a very important determinant in the incidence of IDH. Altering the ultrafiltration rate to achieve a predetermined blood volume profile can reduce the incidence of IDH [43].

It has also been shown that limiting the reduction in plasma osmolarity during hemodialysis by altering the dialysate sodium concentration can enhance hemodynamic stability. In this paradigm, maintaining higher dialysate sodium concentration facilitates the maintenance of adequate intravascular blood volume [44]. The disadvantage to this method is that the higher sodium concentrations increase the amount of sodium available for exchange and may actually increase weight gain and precipitate hypertensive episodes.

As discussed earlier, HD is associated with an increase in core body temperature and concomitant propensity for IDH. Preventing increases in core body temperature allows for a more stable blood pressure throughout the dialysis process [23]. Low temperature diasylate settings (approximately $37-38^{\circ} \mathrm{C}$ ) significantly decrease the severity and frequency of symptomatic IDH [13]. In addition, the low temperature improves capacitance and resistance of peripheral blood vessels and may result in improved cardiac contractility [45]. The use of thermal neutral dialysis reduces the frequency of IDH events by approximately one-fourth.

Several pharmacologic interventions also exist for the treatment of IDH. Midodrine is a prodrug that when metabolized acts as an alpha-1-receptor agonist. It can provide modest increases in both peripheral vascular resistance and cardiac output [46]. It is a well-tolerated medication with the most common side effects being piloerection, scalp itching/burning and nausea. Caution should be taken when administering midrodrine concurrently with negative chronotropic agents including $\beta$-blockers, digoxin and calcium channel blockers. Treatment regimens incorporating midodrine on the days of HD result in significant reductions in both intra- and post-dialytic hypotension [47].

\section{Overview of methylene blue characteristics}

Despite different therapeutic approaches to IDH, a significant proportion of patients undergoing dialysis continue to experience HD-related hypotension. In a quest for effective therapy for IDH, methylene blue (MB) has been evaluated as a potential adjunct in the setting of refractory hypotension. Methylene blue, a "natural pressor", is an 
aromatic chemical compound used in analytical chemistry, biology and medicine. It is a soluble compound that can be administered intravenously or orally/enterally. It functions by inhibiting guanylyl cyclase in vascular smooth muscle, and decreases the levels of cGMP [7, 48-51]. Methylene blue also scavenges nitric oxide and inhibits nitric oxide synthesis $[7,50]$.

\subsection{Pharmacology of methylene blue}

Methylene blue is available in both an intravenous and oral form. Both forms undergo primarily urinary excretion with a half-life of approximately 4-5 hours [52]. Small amounts of $\mathrm{MB}$ are excreted in bile and feces as well [53]. Distribution appears to differ substantially between the two enteral and intravenous forms. Intravenous administration results in significantly higher concentrations within the blood and brain 1 hour after infusion when compared to the oral route. Bioavailability from oral administration ranges from 53-97\% [54]. Oral administration results in much higher concentrations within the bowel wall and liver, with $<3 \%$ of the administered $\mathrm{MB}$ remaining within the intestinal lumen after ingestion. Once in the blood, $\mathrm{MB}$ readily enters erythrocytes where it is reduced to leucomethylene blue at low concentrations. In high concentrations it can act as an oxidizing agent, potentially leading to hemolysis, methemoglobinemia and hyperbilirubinemia [53].

Most side effects of MB appear to be dose-dependent and do not occur with doses below 2 $\mathrm{mg} / \mathrm{kg}$ [55]. Methylene blue can turn urine greenish-blue, and while this may be alarming to patients, it usually resolves within a few days of discontinuing MB. In addition, mild skin discoloration is common, but is self-limiting and treatable with administration of dilute hypochlorite solution [56]. Other side effects may include abdominal pain, nausea, vomiting, headaches, fever, confusion and diaphoresis [54]. Subcutaneous and intradermal injections should be avoided because they have been associated with necrosis and abscess formation [57]. Encephalopathy has been noted in one series that included five patients that received preoperative intravenous $\mathrm{MB}(3-5 \mathrm{mg} / \mathrm{kg}$ in $500 \mathrm{~mL}$ saline) for parathyroid adenoma localization. All five cases of encephalopathy occurred in female patients taking serotonin-metabolism modifying agents [58].

In the neonatal and pediatric populations, enteral $\mathrm{MB}$ administration of $>2 \mathrm{mg} / \mathrm{kg}$ has been associated with severe methemoglobinemia, hemolytic anemia, Heinz body anemia, and hyperbilirubinemia [53]. Anemia following MB administration typically manifests within 24 hours, peaks at 4-5 days and can persist for up to 12 days [59]. Futhermore, photosensitive epithelial desquamation after $\mathrm{MB}$ administration has been reported among infants undergoing phototherapy. This may be due to lysosomal membrane breakdown after interacting with light in the presence of photosensitizing MB [60]. Practitioners caring for patients receiving $\mathrm{MB}$ infusions have to be aware of falsely depressed oxygen saturation readings due to methylene blue interfering with the pulse oximeter's light emission [61].

\subsection{The use of methylene blue in hypotensive patients}

Because of its ability to lower plasma levels of the endogenous vasodilator NO, methylene blue has been investigated in the clinical setting of difficult-to-treat hypotension. Investigational studies of MB in various hypotensive settings have been carried out, with some of the most compelling evidence coming from the areas of cardiac surgery, trauma, renal failure, and other forms of distributive shock. 
Animal models of acute shock have been developed that facilitate objective testing of the role of MB in various forms of shock. Refractory hemorrhagic shock is seen most commonly in trauma patients and carries a high morbidity and mortality. In canine models, untreated animals usually die within 30 minutes of onset of refractory hemorrhagic shock. When treated with an initial bolus of $\mathrm{MB}$ and volume resuscitation the mortality was $0 \%$ at 120 minutes, compared to $75 \%$ for animals treated with volume resuscitation alone [62]. Animals treated with $\mathrm{MB}$ and volume resuscitation maintained significantly higher mean arterial pressures, increased cardiac output, better tissue perfusion, and increased oxygen delivery. Furthermore, MB administration has been associated with significant neurologic and myocardial protective effects during cardiopulmonary resuscitation. This is thought to be due to the effect of $\mathrm{MB}$ contributing to improved coronary perfusion pressure and cardiac index, as well as reduced cerebral perioxidation and inflammation [63].

Hepatic failure may also be complicated by vasoplegia and hypotension. Hepatic failure is commonly associated with increased plasma concentrations of endotoxin in addition to other endogenous vasodilators. Moreover, up to $40 \%$ of patients with cirrhosis develop hepatorenal syndrome within 5 years of initial diagnosis [64]. Published case reports describe the use of $\mathrm{MB}$ in refractory hypotension associated with hepatorenal syndrome, where vasoplegic patients with refractory hypotension were able to become vasopressor free within 5 days of intiation of MB therapy, suggesting a role of increased NO activity in the pathogensis of hepatorenal syndrome-associated vasoplegia [65]. See Figure 2 for a clinical vignette demonstrating $\mathrm{MB}$ use in the setting of difficult-to-treat vasoplegia. For additional information regarding clinical uses of $\mathrm{MB}$ for hypotension in various clinical settings the reader is referred to Table 1 .
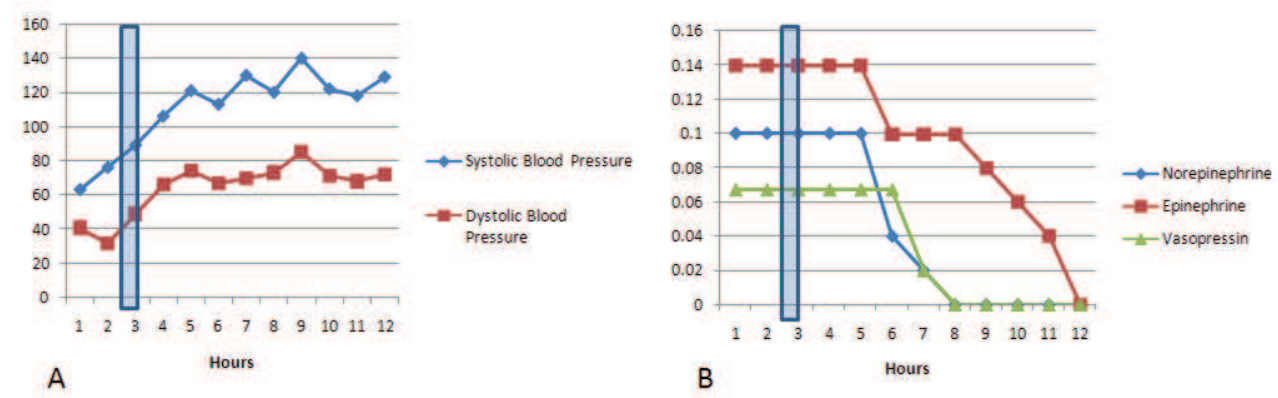

Fig. 2. Hemodynamic profile and vasopressor requirements of a middle-aged vasoplegic male patient after methylene blue (MB) administration. The patient experienced profound hypotension refractory to conventional management on day \#2 following repair of type A aortic dissection. After the patient became essentially unresponsive to escalating vasopressor support, he received an intravenous injection of $2 \mathrm{mg} / \mathrm{kg}$ MB over 30 minutes ( $\mathrm{A}$ and $\mathrm{B}, \mathrm{MB}$ administration timing shaded in blue). A) Blood pressure response to $\mathrm{MB}$ injection showing increase in both systolic and diastolic blood pressures. B) Vasopressor doses immediately prior, during, and after MB infusion. All vasopressors were weaned completely within 9 hours of MB administration. Legend: MB - methylene blue; Infusion rates - Vasopressin units/min; Epinephrine - $\mathrm{mcg} / \mathrm{kg} /$ minute; Norepinephrine $\mathrm{mcg} / \mathrm{kg} /$ minute; Blood pressure listed in $\mathrm{mmHg}$. 
\begin{tabular}{|l|l|l}
\hline \hline Author (ref, & Clinical Setting & Major results/findings \\
\hline
\end{tabular}

$(6,2001)$

它

\begin{tabular}{|} 
\\
\\
\hline \hline Preiser \\
$(67,1995)$
\end{tabular}

$(67,1995)$

Gubbels

$(68,1995)$
Investigational study of $\mathrm{MB}$

administration in HD patients. ( $n=41$,

18 HD patients with hypotension, 18

HD patients without hypotension, and

5 healthy controls).

$\mathrm{MB}$ was given as a bolus $(1 \mathrm{mg} / \mathrm{kg})$

followed by an infusion $(0.1 \mathrm{mg} / \mathrm{kg})$

for 210 minutes until the end of HD

session. On non-dialsysis days, only

the bolus dose was given.

Prospective medical-surgical ICU

study involving patients with

hypotension refractory to vasopressor

therapy $(\mathrm{n}=14)$.

$\mathrm{MB}$ was given as a bolus $(2 \mathrm{mg} / \mathrm{kg})$

over 15 minutes. Additional dose was

needed in 6 patients due to transient

response to the initial bolus.

Non-randomized clinical trial

involving $\mathrm{MB}$ administration in the

setting of sepsis. The trial involved

consecutive patients with a pulmonary

catheter in place $(n=9)$.

MB was administered as an

intravenous bolus ( $2 \mathrm{mg} / \mathrm{kg})$.
In hypotension-prone patients, MB prevent the hypotension during dialysis and increas both systolic and diastolic blood pressure or non-dialysis days.

In normotensive patients, MB increased blo pressure during the first hour of dialysis an during the first 90 minutes on non-dialysis $c$ The blood pressure in healthy controls remained unchanged.

MB administration was associated with increased mean arterial pressure and increa systemic vascular resistance. A decrease in serum lactate following $\mathrm{MB}$ administration noted.

MB administration resulted in increased me arterial pressure and oxygen uptake as well decrease in arterial complaiance.

$\mathrm{MB}$ use was also associated with increased myocardial function and oxygen delivery. 


\begin{tabular}{|l|l|l}
\hline Author (ref, & Clinical Setting & Major results/findings \\
\hline
\end{tabular}

Report describing MB use in

$(65,2008)$

vasoplegic patients with

simulataneous hepatic and renal

failure.

One patient received $\mathrm{MB}$ bolus (1 $\mathrm{mg} / \mathrm{kg}$ ) followed by another dose of

$0.5 \mathrm{mg} / \mathrm{kg}$ at 12 hours. Another patient received $\mathrm{MB}$ infusion of 1 $\mathrm{mg} / \mathrm{kg}$, followed by an enteral-based $\mathrm{MB}$ regimen $(1 \mathrm{mg} / \mathrm{kg}$ every 12 hours).

Jaskille $(69,2008)$

Case series of patients with severe burns (80-95\% TBSA, $n=2)$ and persistent hypotension despite simultaneous vasopressin and norepinephrine.

Patient received single intravenous infusion $(2 \mathrm{mg} / \mathrm{kg})$ of MB.

Del Duca

$(70,2009)$

Case series of patients with intraoperative anaphylaxis during cardiac surgery. One case was a reaction to protamine, the other was a reaction to aprotinin.

The patients were treated with intravenous MB (2mg/kg).
Both patients experienced significant hemodynamic improvement following MB administration.

The first patient was successfully weaned of dual vasopressin-norepinephrine regimen. The second patient was able to leave the hospital and receive palliative care at home to his ability to be vasopressor-free utilizing enteral (oral) methylene blue regimen.

Response to MB noted within 30 minutes. Significant reductions in pressor requiremer including complete resolution of vasoplegia within 2 hours in 1 patient.

Both patients had prompt resolution of hypotension and did not require additional doses. There were no adverse effects. 


\subsection{The use of methylene blue in hemodialysis and intradialyitc hypotension}

The use of $\mathrm{MB}$ may reduce the incidence of IDH in patients who are prone to this hemodynamic disorder [6]. Initial studies utilized a pre-HD bolus of MB and noticed lower incidence of intra- and post-dialytic hypotensive episodes. When given continuously to hypotension prone patients during $\mathrm{HD}$, episodes of IDH were significantly reduced. Of interest, $\mathrm{MB}$ administration to normal controls did not cause appreciable changes in blood pressure, which corroborates the role of nitrate generation during HD as contributory to IDH.

As discussed earlier, there is usually a reduction in circulating plasma nitrates during HD procedure [66]. However, following the procedure certain patients appear more prone to the development of circulating nitrate increases. Among patients who are more prone to develop IDH, a significant increase in nitrate production was noted on post-dialysis day 1 compared to dialysis patients who are not prone to hypotension $(1.21+/-0.13 \mu \mathrm{mol} / \mathrm{min}$ versus $0.61+/-0.11 \mu \mathrm{mol} / \mathrm{min}$ ) [6]. In addition, when patients with propensity for IDH were treated with $\mathrm{MB}$ during the procedure, their 24-hour plasma nitrate production decreased significantly compared to untreated individuals, further supportiny the role of NO production and cGMP mediated pathways for the development of IDH.

\section{Conclusions}

Intradialytic hypotension continues to be a significant challenge. Despite multiple therapies, no single agent or modality has been proven universally effective in the management of IDH. For patients who are refractory to traditional therapies (fluid infusions, vasopressor administration, modification of ultrafiltration rates) adjunctive treatments may hold promise. One of those approaches is the use of methylene blue, an inhibitor of guanylyl cyclase in vascular smooth muscle, as well as nitric oxide synthesis inhibitor and scavenger. Although early research in this promising area is encouraging, further investigation is needed before more widespread implementation of this therapy is undertaken.

\section{References}

[1] Tonelli, M., et al., Chronic kidney disease and mortality risk: a systematic review. J Am Soc Nephrol, 2006. 17(7): p. 2034-47.

[2] Collins, A.J., et al., Excerpts from the United States Renal Data System 2006 Annual Data Report. Am J Kidney Dis, 2007. 49(1 Suppl 1): p. A6-7, S1-296.

[3] Foley, R.N. and A.J. Collins, End-stage renal disease in the United States: an update from the United States Renal Data System. J Am Soc Nephrol, 2007. 18(10): p. 2644-8.

[4] Foley, R.N., P.S. Parfrey, and M.J. Sarnak, Clinical epidemiology of cardiovascular disease in chronic renal disease. Am J Kidney Dis, 1998. 32(5 Suppl 3): p. S112-9.

[5] Schreiber, M.J., Jr., Setting the stage. Am J Kidney Dis, 2001. 38(4 Suppl 4): p. S1-S10.

[6] Peer, G., et al., Methylene blue, a nitric oxide inhibitor, prevents haemodialysis hypotension. Nephrol Dial Transplant, 2001. 16(7): p. 1436-41.

[7] Stawicki, S.P., et al., Methylene blue and vasoplegia: who, when, and how? Mini Rev Med Chem, 2008. 8(5): p. 472-90. 
[8] Shoji, T., et al., Hemodialysis-associated hypotension as an independent risk factor for two-year mortality in hemodialysis patients. Kidney Int, 2004. 66(3): p. 1212-20.

[9] Lins, L.E., et al., Blood pressure reduction during hemodialysis correlates to intradialytic changes in plasma volume. Clin Nephrol, 1992. 37(6): p. 308-13.

[10] Santoro, A., et al., Blood volume controlled hemodialysis in hypotension-prone patients: a randomized, multicenter controlled trial. Kidney Int, 2002. 62(3): p. 1034-45.

[11] Koomans, H.A., A.B. Geers, and E.J. Mees, Plasma volume recovery after ultrafiltration in patients with chronic renal failure. Kidney Int, 1984. 26(6): p. 848-54.

[12] Perazella, M.A., Approach to patients with intradialytic hypotension: a focus on therapeutic options. Seminars in Dialysis, 1999. 12(3): p. 175-181.

[13] Jost, C.M., et al., Effects of cooler temperature dialysate on hemodynamic stability in "problem" dialysis patients. Kidney Int, 1993. 44(3): p. 606-12.

[14] Sinha, A.D., R.P. Light, and R. Agarwal, Relative plasma volume monitoring during hemodialysis AIDS the assessment of dry weight. Hypertension, 2010. 55(2): p. 305-11.

[15] Jaeger, J.Q. and R.L. Mehta, Assessment of dry weight in hemodialysis: an overview. J Am Soc Nephrol, 1999. 10(2): p. 392-403.

[16] Kuhlmann, M.K., et al., Bioimpedance, dry weight and blood pressure control: new methods and consequences. Curr Opin Nephrol Hypertens, 2005. 14(6): p. 543-9.

[17] Hampl, H., et al., Hemodynamics during hemodialysis, sequential ultrafiltration and hemofiltration. J Dial, 1979. 3(1): p. 51-71.

[18] Nishimura, M., et al., Enhanced production of nitric oxide may be involved in acute hypotension during maintenance hemodialysis. Am J Kidney Dis, 1998. 31(5): p. 80917.

[19] Kurnatowska, I. and M. Nowicki, Serum chromogranin A concentration and intradialytic hypotension in chronic haemodialysis patients. Int Urol Nephrol, 2006. 38(3-4): p. 7015.

[20] Krishnan, A.V. and M.C. Kiernan, Uremic neuropathy: clinical features and new pathophysiological insights. Muscle Nerve, 2007. 35(3): p. 273-90.

[21] Imai, E., et al., Adenosine A1 receptor antagonist improves intradialytic hypotension. Kidney Int, 2006. 69(5): p. 877-83.

[22] Giaime, P., et al., Relationship between A2A adenosine receptor expression and intradialytic hypotension during hemodialysis. J Investig Med, 2006. 54(8): p. 473-7.

[23] Schneditz, D., Temperature and thermal balance in hemodialysis. Semin Dial, 2001. 14(5): p. 357-64.

[24] Maggiore, Q., Isothermic dialysis for hypotension-prone patients. Semin Dial, 2002. 15(3): p. 187-90.

[25] Pelosi, G., et al., Impaired sympathetic response before intradialytic hypotension: a study based on spectral analysis of heart rate and pressure variability. Clin Sci (Lond), 1999. 96(1): p. 23-31.

[26] Fine, A. and B. Penner, The protective effect of cool dialysate is dependent on patients' predialysis temperature. Am J Kidney Dis, 1996. 28(2): p. 262-5.

[27] Hoenich, N.A. and N.W. Levin, Can technology solve the clinical problem of 'dry weight'? Nephrol Dial Transplant, 2003. 18(4): p. 647-50. 
[28] Stawicki, S.P., et al., Intensivist use of hand-carried ultrasonography to measure IVC collapsibility in estimating intravascular volume status: correlations with CVP. J Am Coll Surg, 2009. 209(1): p. 55-61.

[29] Evans, D.C., et al., Complications associated with pulmonary artery catheters: a comprehensive clinical review. Scand J Surg, 2009. 98(4): p. 199-208.

[30] Reddan, D.N., et al., Intradialytic blood volume monitoring in ambulatory hemodialysis patients: a randomized trial. J Am Soc Nephrol, 2005. 16(7): p. 2162-9.

[31] Kayatas, M., et al., Comparison of the non-invasive methods estimating dry weight in hemodialysis patients. Ren Fail, 2006. 28(3): p. 217-22.

[32] Lin, S.H., et al., Increased nitric oxide production in hypotensive hemodialysis patients. ASAIO J, 1996. 42(5): p. M895-9.

[33] Rysz, J., et al., Nitric oxide release in the peripheral blood during hemodialysis. Kidney Int, 1997. 51(1): p. 294-300.

[34] Amore, A. and R. Coppo, Nitric oxide production with PMMA membrane. Contrib Nephrol, 1999. 125: p. 182-96.

[35] Noris, M., et al., Enhanced nitric oxide synthesis in uremia: implications for platelet dysfunction and dialysis hypotension. Kidney Int, 1993. 44(2): p. 445-50.

[36] Kang, E.S., et al., Hemodialysis hypotension: interaction of inhibitors, iNOS, and the interdialytic period. Am J Med Sci, 1999. 317(1): p. 9-21.

[37] Brunini, T.M., et al., Platelet nitric oxide synthesis in uremia and malnutrition: a role for Larginine supplementation in vascular protection? Cardiovasc Res, 2007. 73(2): p. 359-67.

[38] Finkel, M.S., et al., Negative inotropic effects of cytokines on the heart mediated by nitric oxide. Science, 1992. 257(5068): p. 387-9.

[39] Balligand, J.L., et al., Control of cardiac muscle cell function by an endogenous nitric oxide signaling system. Proc Natl Acad Sci U S A, 1993. 90(1): p. 347-51.

[40] Cavalcanti, S., et al., Model-based study of the effects of the hemodialysis technique on the compensatory response to hypovolemia. Kidney Int, 2004. 65(4): p. 1499-510.

[41] Fleming, S.J., et al., Blood volume change during isolated ultrafiltration and combined ultrafiltration-dialysis. Nephrol Dial Transplant, 1988. 3(3): p. 272-6.

[42] Passlick-Deetjen, J., C. Baldamus, and W. Ries, Changes in blood volume and blood pressure: an indicator for symptomatic hypotension. J Am Soc Nephrol, 1999. A1507: p. 298A.

[43] van der Sande, F.M., J.P. Kooman, and K.M. Leunissen, Intradialytic hypotension--new concepts on an old problem. Nephrol Dial Transplant, 2000. 15(11): p. 1746-8.

[44] Rodrigo, F., et al., Osmolality changes during hemodialysis. Natural history, clinical correlations, and influence of dialysate glucose and intravenous mannitol. Ann Intern Med, 1977. 86(5): p. 554-61.

[45] Levy, F.L., et al., Improved left ventricular contractility with cool temperature hemodialysis. Kidney Int, 1992. 41(4): p. 961-5.

[46] Hoeben, H., et al., Hemodynamics in patients with intradialytic hypotension treated with cool dialysate or midodrine. Am J Kidney Dis, 2002. 39(1): p. 102-7.

[47] Cruz, D.N., Midodrine: a selective alpha-adrenergic agonist for orthostatic hypotension and dialysis hypotension. Expert Opin Pharmacother, 2000. 1(4): p. 835-40. 
[48] Oliveira Neto, A.M., et al., Methylene blue: an effective treatment for contrast mediuminduced anaphylaxis. Med Sci Monit, 2003. 9(11): p. CS102-6.

[49] Marczin, N., U.S. Ryan, and J.D. Catravas, Methylene blue inhibits nitrovasodilator- and endothelium-derived relaxing factor-induced cyclic GMP accumulation in cultured pulmonary arterial smooth muscle cells via generation of superoxide anion. J Pharmacol Exp Ther, 1992. 263(1): p. 170-9.

[50] Evora, P.R., C.H. Roselino, and P.M. Schiaveto, Methylene blue in anaphylactic shock. Ann Emerg Med, 1997. 30(2): p. 240.

[51] Palmer, R.M., The discovery of nitric oxide in the vessel wall. A unifying concept in the pathogenesis of sepsis. Arch Surg, 1993. 128(4): p. 396-401.

[52] Peter, C., et al., Pharmacokinetics and organ distribution of intravenous and oral methylene blue. Eur J Clin Pharmacol, 2000. 56(3): p. 247-50.

[53] Allegaert, K., et al., Methemoglobinemia and hemolysis after enteral administration of methylene blue in a preterm infant: relevance for pediatric surgeons. J Pediatr Surg, 2004. 39(1): p. E35-7.

[54] Shanmugam, G., Vasoplegic syndrome--the role of methylene blue. Eur J Cardiothorac Surg, 2005. 28(5): p. 705-10.

[55] Andresen, M., et al., Use of methylene blue in patients with refractory septic shock: impact on hemodynamics and gas exchange. J Crit Care, 1998. 13(4): p. 164-8.

[56] Clifton, J., 2nd and J.B. Leikin, Methylene blue. Am J Ther, 2003. 10(4): p. 289-91.

[57] Stradling, B., G. Aranha, and S. Gabram, Adverse skin lesions after methylene blue injections for sentinel lymph node localization. Am J Surg, 2002. 184(4): p. 350-2.

[58] Sweet, G. and S.B. Standiford, Methylene-blue-associated encephalopathy. J Am Coll Surg, 2007. 204(3): p. 454-8.

[59] Albert, M., M.S. Lessin, and B.F. Gilchrist, Methylene blue: dangerous dye for neonates. J Pediatr Surg, 2003. 38(8): p. 1244-5.

[60] Porat, R., S. Gilbert, and D. Magilner, Methylene blue-induced phototoxicity: an unrecognized complication. Pediatrics, 1996. 97(5): p. 717-21.

[61] Kessler, M.R., et al., Spurious pulse oximeter desaturation with methylene blue injection. Anesthesiology, 1986. 65(4): p. 435-6.

[62] Ghiassi, S., et al., Methylene blue enhancement of resuscitation after refractory hemorrhagic shock. J Trauma, 2004. 57(3): p. 515-21.

[63] Miclescu, A., S. Basu, and L. Wiklund, Methylene blue added to a hypertonic-hyperoncotic solution increases short-term survival in experimental cardiac arrest. Crit Care Med, 2006. 34(11): p. 2806-13.

[64] Lenz, K., et al., Ornipressin in the treatment of functional renal failure in decompensated liver cirrhosis. Effects on renal hemodynamics and atrial natriuretic factor. Gastroenterology, 1991. 101(4): p. 1060-7.

[65] Bosoy, D., et al., Utilization of methylene blue in the setting of hypotension associated with concurrent renal and hepatic failure: A concise review. OPUS 12 Scientist, 2008. 2(1): p. 21-29.

[66] Martensson, L., J. Hegbrant, and H. Thysell, Generation of nitrate during dialysis as a measure of nitric oxide synthesis. Artif Organs, 1997. 21(2): p. 163-7. 
[67] Preiser, J.C., et al., Methylene blue administration in septic shock: a clinical trial. Crit Care Med, 1995. 23(2): p. 259-64.

[68] Daemen-Gubbels, C.R., et al., Methylene blue increases myocardial function in septic shock. Crit Care Med, 1995. 23(8): p. 1363-70.

[69] Jaskille, A.D., et al., Methylene blue in the treatment of vasoplegia following severe burns. Journal of Burn Care \& Research, 2008. 29(2):408-10.

[70] Del Duca, D., et al., Use of methlene blue for catecholamine-refractory vasoplegia from protamine and aprotinin. Ann Thorac Surg, 2009. 87: p. 640-2. 


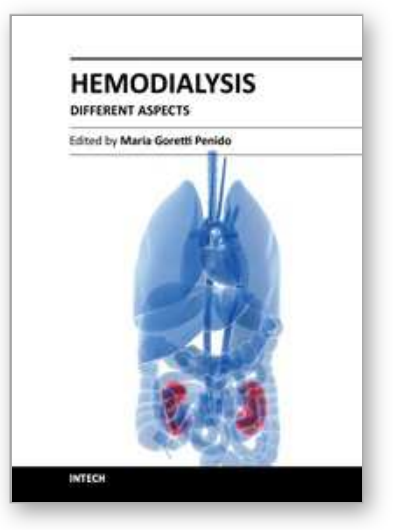

\author{
Hemodialysis - Different Aspects \\ Edited by Prof. Maria Goretti Penido
}

ISBN 978-953-307-315-6

Hard cover, 321 pages

Publisher InTech

Published online 14, November, 2011

Published in print edition November, 2011

The book provides practical and accessible information on all aspects of hemodialysis, with emphasis on dayto-day management of patients. It is quite comprehensive as it covers almost all the aspects of hemodialysis. In short it is a valuable book and an essential aid in the dialysis room.

\title{
How to reference
}

In order to correctly reference this scholarly work, feel free to copy and paste the following:

Wisler J. R. and Stawicki S. P. A. (2011). Methylene Blue and Dialysis-Related Hypotension, Hemodialysis Different Aspects, Prof. Maria Goretti Penido (Ed.), ISBN: 978-953-307-315-6, InTech, Available from: http://www.intechopen.com/books/hemodialysis-different-aspects/methylene-blue-and-dialysis-relatedhypotension

\section{INTECH}

open science | open minds

\section{InTech Europe}

University Campus STeP Ri

Slavka Krautzeka 83/A

51000 Rijeka, Croatia

Phone: +385 (51) 770447

Fax: +385 (51) 686166

www.intechopen.com

\section{InTech China}

Unit 405, Office Block, Hotel Equatorial Shanghai

No.65, Yan An Road (West), Shanghai, 200040, China

中国上海市延安西路65号上海国际贵都大饭店办公楼405单元

Phone: +86-21-62489820

Fax: +86-21-62489821 
(C) 2011 The Author(s). Licensee IntechOpen. This is an open access article distributed under the terms of the Creative Commons Attribution 3.0 License, which permits unrestricted use, distribution, and reproduction in any medium, provided the original work is properly cited. 